\title{
Erratum to: Effect of Jasmonic Application on Economically Insect Pests and Yeald in Spring Wheat
}

\author{
Nabil E. El-Wakeil · Christa Volkmar
}

Online publiziert: 1. August 2012

(C) Springer-Verlag 2012

\section{Erratum to: Gesunde Pflanzen}

DOI: 10.1007/s10343-012-0278-x

There is a typo in Schlüsselwörter. Jasmona should be written Jasmonat.

In the German title reads "Jasmonasäure-..." but should be writen "Jasmonsäure".

The online version of the article can be found under doi:10.1007/s10343-012-0278-x

Dr. N. E. El-Wakeil $(\bowtie) \cdot$ C. Volkmar Institute of Agriculture and Nutritional Sciences,

Martin-Luther-University Halle-Wittenberg, Halle, Germany

e-mail: nabil.el-wakeil@landw.uni-halle.de

Dr. N. E. El-Wakeil

Pests and Plant Protection Department, National Research Center,

Cairo, Dokki, Egypt 